\title{
Hand Pain and Trigger Finger Due to Ganglion Cyst: An Ultrasound-Guided Diagnosis and Injection
}

\section{TO THE EDITOR:}

A 54-year-old woman was seen due to hand pain and locking in her right third finger. Palpation of the third metacarpophalangeal joint was painful. Laboratory tests including acute phase reactants were within normal ranges. Ultrasound imaging illustrated a peritendinous ganglion cyst causing trigger finger (Fig. 1). Ultrasound-guided corticosteroid injection (peritendinous) was carried out and control visits were recommended.

Trigger finger is the blocking of tendon gliding at the pulley and usually seen due to stenosing tenosynovitis and thickening of the pulleys. Degenerative changes, rheumatic diseases, and trauma can be the underlying etiologic factors (1). Ganglion cyst (synovial cyst) is the benign tumor-like mass seen nearby the synovial tissues (tendon sheath or joint) and can cause trigger finger as well $(2,3)$. Tenderness, nodules, and locking are the main physical findings. As for the imaging methods, $x$-rays can be the initial modality to exclude bony pathologies (e.g., osteophytes, erosions, exostosis). Computed tomography and magnetic resonance imaging can be required for further examinations to highlight the etiology $(1,3)$. On the other hand, ultrasound can be readily used to illustrate the etiologic factors of trigger finger owing to its several advantages; easy applicable, high spatial resolution, providing dynamic imaging and sonopalpation, repeatable, and guiding interventions. Treatment options depend on the etiologic factor, yet release of the pulleys and injections are the most common approaches.
Murat Kara, MD

Associate Professor

Ankara Physical Medicine and Rehabilitation

Training and Research Hospital

Ankara, Turkey

E-mail: mkaraftr@yahoo.com

Timur Ekiz, MD

Ankara Physical Medicine and Rehabilitation Training and Research Hospital

Ankara, Turkey

E-mail: timurekiz@gmail.com

Hatice Gozde Sumer, MD

Ankara Physical Medicine and Rehabilitation Training and Research Hospital

Ankara, Turkey

E-mail: gzdsmr@hotmail.com

\section{References}

1. Parmaksızolu F, Cansü E, Ünal MB. Trigger finger at the carpal tunnel level: Three case reports. Acta Orthop Traumatol Turc 2013; 47:65-67.

2. Ekiz T, Öztürk GT, Yalçın S, Kınıklı G, Özçakar L. Ultrasonographic diagnosis of posterior interosseous nerve entrapment due to ganglion cyst in a patient with rheumatoid arthritis. Rheumatol (Oxford) 2014; doi:10.1093/rheumatology/keu342 [e-pub ahead of print].

3. Vuillemin V, Guerini H, Morvan G. Musculoskeletal interventional ultrasonography: The upper limb. Diagn Interv Imaging 2012; 93:665-673.

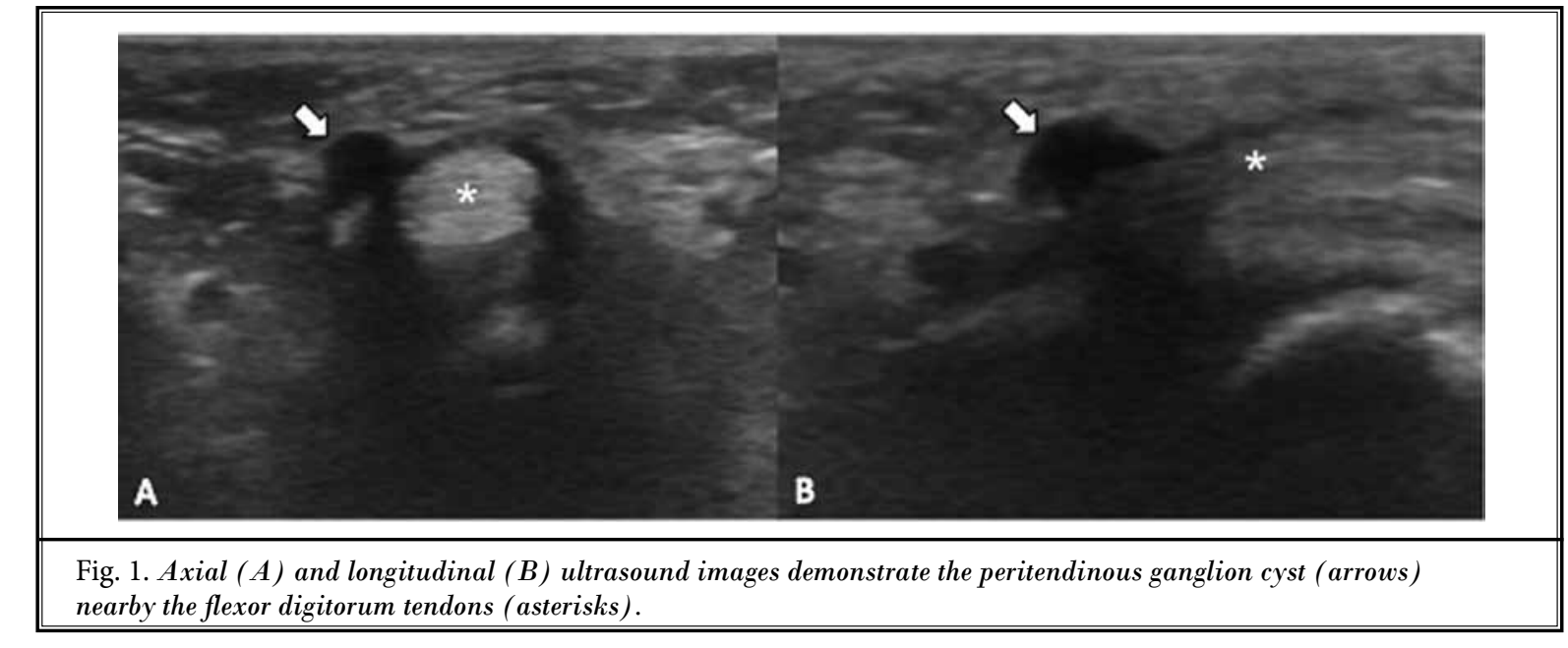

